\title{
Some Thoughts on Changing Comparative Advantage
}

Gerard K. Boon

\section{Introduction}

In the next two decades the pace of automation in the industrialised countries will increase significantly as a consequence of current developments in microelectronic technology and a diffusion of elements of this technology to virtually all producer and consumer goods industries. The speed of diffusion is accelerating and will probably attain a momentum which can neither be stopped or reversed. The most important feature of this technological development insofar as manufacturing industry is concerned is that it enables the automation of the 'discrete parts' industry. This industry produces products which are assembled from smaller parts. Therefore, after automation, these industries will become comparable to capital intensive continuous process sectors such as chemicals, petrochemicals and cement. The discrete part industry, in its production and assembly phase, provides the bulk of the industrial employment in all industrialised countries. A segment of this industry, particularly that which produces capital goods and technology, is highly labour- and skill-intensive. In this type of output, the comparative advantage of the industrialised world is high.

Another characteristic of the microelectronic technological revolution is that it is diffusing to the service and agricultural sectors as well as in industry. It therefore poses a formidable adjustment problem to the societies of the developed world, who will most probably have to undergo changes in structure in order to cope with the sharp reduction in formal employment which automation involves.

Since the technological change with which we are dealing is, in my view, of such importance that it will evoke changes in the structure of both developed and developing societies alike, it will have an inevitable impact on comparative advantage, invalidating the ceteris paribus assumption of trade theory. It is therefore more realistic to assume that everything else will change, as a direct and indirect consequence of this microelectronic technological change. Hence, whilst comparative advantage will also change, the question is how, and to which extent? The short answer would be, nobody knows! Nevertheless it is worth assessing the question in more detail, since it clearly is of utmost importance.

\section{The present international division of labour}

According to the neo-classical theory of international trade, the so-called international division of labour is based on differences among nations and regions in relative comparative advantage in the production of outputs. Indeed, it has been mathematically 'proved' (under the very abstract and restricted conditions of this theory) that in the long run international trade equalises the incomes of capital and labour in all countries. However, there is, as usual, a large discrepancy between theory and practice, and the theory is probably more useful in explaining the past than the present. A major reason for this discrepancy between theory and the real world of international trade is the politics of international and national relations. In other words, it is not only economic factors which play a role, but also political ones, which are, in turn, influenced by power and other social and cultural relations. Thus, according to economic theory, protectionism will lead to a loss in welfare, but trade unions, representing workers in economic sectors which have to decline or disappear, may feel differently.

Developing countries, on the basis of neo-classical trade theory, should in some cases refrain from entering into certain capital-intensive production activities. However their governments may feel differently. Strategic considerations as well as economic ones may dictate national development objectives which contrast with those suggested by international trade theory. This implies that trade theory, and with it the concept of comparative advantage, has to be modified. It must be seen not only in a purely economic context, but together with extra economic considerations of a social, political and cultural nature. The drawback of introducing a more complex concept of comparative advantage is that it becomes less clear-cut and therefore less powerful as an explanatory theory. Despite these reservations, the neo-classical concept of comparative advantage still has some explanatory and practical significance, as I have shown in my own research on international trade in footwear, fibres, textiles and clothing, as well as on the technologies making these products [Boon 1980a, 1981]. One of the conclusions which I reached was that the output specification of the traded goods is the major explanatory variable. Hence goods with simple output specifications are the ones in which less-industrialised and newly industrial- 
ising countries have, in principle, a comparative advantage, whilst mature industrialised countries have an advantage in goods with complex specifications and characteristics. This basic principle holds not only for industrial products, but for all activities and outputs which are tradeable, including intangible services, know-how and information [Boon 1981, 1982].

Thus I believe that the major factor explaining comparative advantage is the difference in output specifications rather than in the price differential between labour and capital in different countries, which, according to neo-classical trade theory, is the major explanatory parameter. Nevertheless all this is still subject to the constraints mentioned-political, social and cultural considerations may outweigh economic ones in explaining actual trade patterns.

\section{The future}

How will the diffusion of future technological advances, specifically of those resulting from the application of microelectronics, affect international trade? Such a very generally formulated question is hard to answer and we have to break it down into smaller components. The effects clearly will depend on the diffusion of microelectronic technology into other processing technologies and products. Let us start with the latter, the out puts. The demand for final outputs is enhanced if their price is falling for equal utilities (say quality), or if qualities, yielding higher consumer satisfaction, are increasing for equal prices, or when prices and qualities for the consumer both improve. Hence, if the application of technology embodying microelectronic components allows producers to achieve any or all of the objectives mentioned, they will be anxious to acquire this new technology.

Diffusion cannot be explained by prices, qualities, demands and supplies (ie market forces) alone, since all these occur in particular social-economic environments, which in turn are conditioned by the formalised and non-formalised institutional frameworks which define a society. Clearly societies differ, and therefore the rate at which technology diffuses differs amongst countries, whether located in the North or in the South. Different diffusion rates among countries imply future differences in comparative advantage and therefore a potential basis for international trade. Let us first examine the North.

\section{The North}

The North consists of North America, Japan, Western Europe and the socialist countries. Microelectronics technology is most strongly developed, diffused and applied in the USA (where it originated) and Japan. Both are engaged in intense competition, both are market economies, dynamically oriented and aggressive. Both countries are about equal in strength as far as microelectronic capability is concerned, with the US probably somewhat stronger in the development of the technology and Japan in the application. In Europe the scene is rather different, since it neither adheres to a dynamically or aggressively market oriented ideology and economic system nor is it socialist in the Eastern European sense. It lies somewhere in between these extremes.

The diffusion of microelectronic technology in Western Europe will therefore be slower than in Japan and the US, but considerably faster than in Eastern Europe. This could imply a further weakening of the alliance of the free market economies and a drifting away of Western Europe towards a degree of economic and political neutrality. Moreover, on the basis of projected differences in the rate of diffusion of the new technology in the US, Japan, Western and Eastern Europe, comparative advantages among these areas will be affected accordingly. This will ultimately result in increasing technological dependence, and hence economic dependence, and, in the somewhat longer run, possibly some erosion of the political power of the Western- and Eastern European areas. But clearly the extent to which this occurs depends on Western Europe's responce to the challlenge, and this cannot be completely foreseen.

\section{The South}

What about the South? Clearly we also have to make some differentiation here. Not all countries are at the same stage of development: in one group are the newly industrialising countries (NICs) such as Taiwan, South Korea, Singapore, Mexico, Brazil, Argentina and India; and in the other group are the remaining countries, which are at a lower level of industrial development. Whilst such a distinction is very general, we cannot here discuss the subject in any other way than by using such high levels of aggregates.

In some of the NICs certain capital goods containing microelectronic elements are already produced. It is conceivable even that some of these countries (eg Taiwan and South Korea) will become exporters of relatively simple capital goods (machine tools for example), containing microelectronic components. In fact, this already occurs to some extent. It is even conceivable that a select number of the NICs may become 'developed'. However, unlike South Korea and Taiwan, the economies of Mexico, Brazil and India have a much more dualistic, even pluralistic, structure and it will be some time before they qualify for admission into the club of the rich countries. In my view microelectronic technology will not diffuse that rapidly in this latter group of countries, and only the best enterprises (as to internal organisation and quality 
of output) will experience relatively rapid diffusion. The basic reason for this is that the new technology is a geo-technology of the North, conditioned by the particular situation in that industrial area and therefore appropriate as an output and an input there. Only enterprises with a comparable conditioning in the South, (such as affiliated firms of multinational companies or national companies exporting and competing on the world market with the North) will introduce the new technology. Moreover in Latin America the NICs tend to have a more inward looking development strategy and, therefore, in some cases the new technology will diffuse on the basis of nonprivate economic feasibility criteria, to increase the local technological capabilities and to decrease technological dependence. Similar considerations may play a role for India. In the remaining countries of the South the diffusion of the new technology will be even more restricted.

\section{North-South}

Finally, exploring North-South interrelations, particularly their trading relations, how will automation on the basis of microelectronics influence comparative advantage?

Let us first focus on a more general point already mentioned. The new technology, involving the full or partial use of microelectronics, is a geo-technology of the North, particularly of the USA and Japan, and is particularly appropriate to those areas. Clearly it is a considerably less appropriate technology for areas with a different culture or economic environment. (A few exceptions have already been mentioned.) In such a situation the North always tends to increase its comparative advantage in the production and application of the new technology, and the NICs and the rest of the South face a deterioration in their comparative advantage.

In the face of this growing technological gap, how will the international division of labour in industrial and other products be affected by this new technology? I stated above that output specialisation is the major factor underlying comparative advantage. This product specification is now dispersed over the world in the following way: simpler outputs with common specifications have become the speciality of the developing countries, whilst outputs with specific characteristics as to quality, colour, smell, taste, fashion, and more sophisticated production technologies (all of which are characteristics of the discrete parts industry) have become the speciality of the developed countries. At present it looks as if the new microelectronics technology is particularly suitable for the production of these special outputs, and less so for the production of common outputs which can be mass produced on conventional automated machinery requiring little skill. Therefore, the use of the new technology for the relatively small batch production of discrete parts will inhibit a tendency for these outputs also to move to the newly industrialising countries. Thus the new technology will enable the North to remain competitive in its present output specification for some time to come.

The simpler, more mass produced outputs, have generally speaking already moved to the NICs. In this output new technological advances based on microelectronic components diffuse more slowly, and therefore for the immediate and near future, there is no reason to believe that the international division of labour will be reversed. In certain cases a roll-back of the international division of labour has occurred, but mostly it concerns assembly rather than production activities and these are exceptions rather than the rule. However, for mass produced products now produced by fixed rather than flexible production systems, changes in production technology will undoubtedly also occur. Since these systems are already labour-extensive, the introduction of more flexible technology will enable greater variety in the product mix, which is an aspect of quality and fashion, rather than a displacement of labour and hence a reduction in the cost of production. But the introduction of robots in manufacturing and assembly, through its impact on labour utilisation, will nevertheless have an effect on comaprative advantage since the international division of labour in certain industrial processes occurs precisely because labour in the North virtually refuses to undertake certain tasks on the grounds that the work is unhealthy, dangerous, extremely boring or a combination of all three. The introduction of robots for this type of work is advancing rapidly in the North, and the South consequently stands to lose as a result. Further, decisions to move production to lower labourcost areas are based not only on labour cost differentials, but more importantly on other factors, such as docility of the labour force, and the opportunity to operate on a multiple shift basis. Since numerically controlled machinery and robots can work 24 hours a day with little or no supervision, the comparative advantage of the North will benefit accordingly.

As I suggested earlier, the new technology will diffuse in the various countries in the North and the South at different rates. This implies that there will be all kinds of segments and niches where, on the basis of the output-speciality-comparative advantage criterion, international trade is bound to flourish. Further, if the diffusion of the new technology in the North does have a dramatic impact on formal employment opportunities, new social contracts in the North will be imperative. Almost certainly more leisure time for 


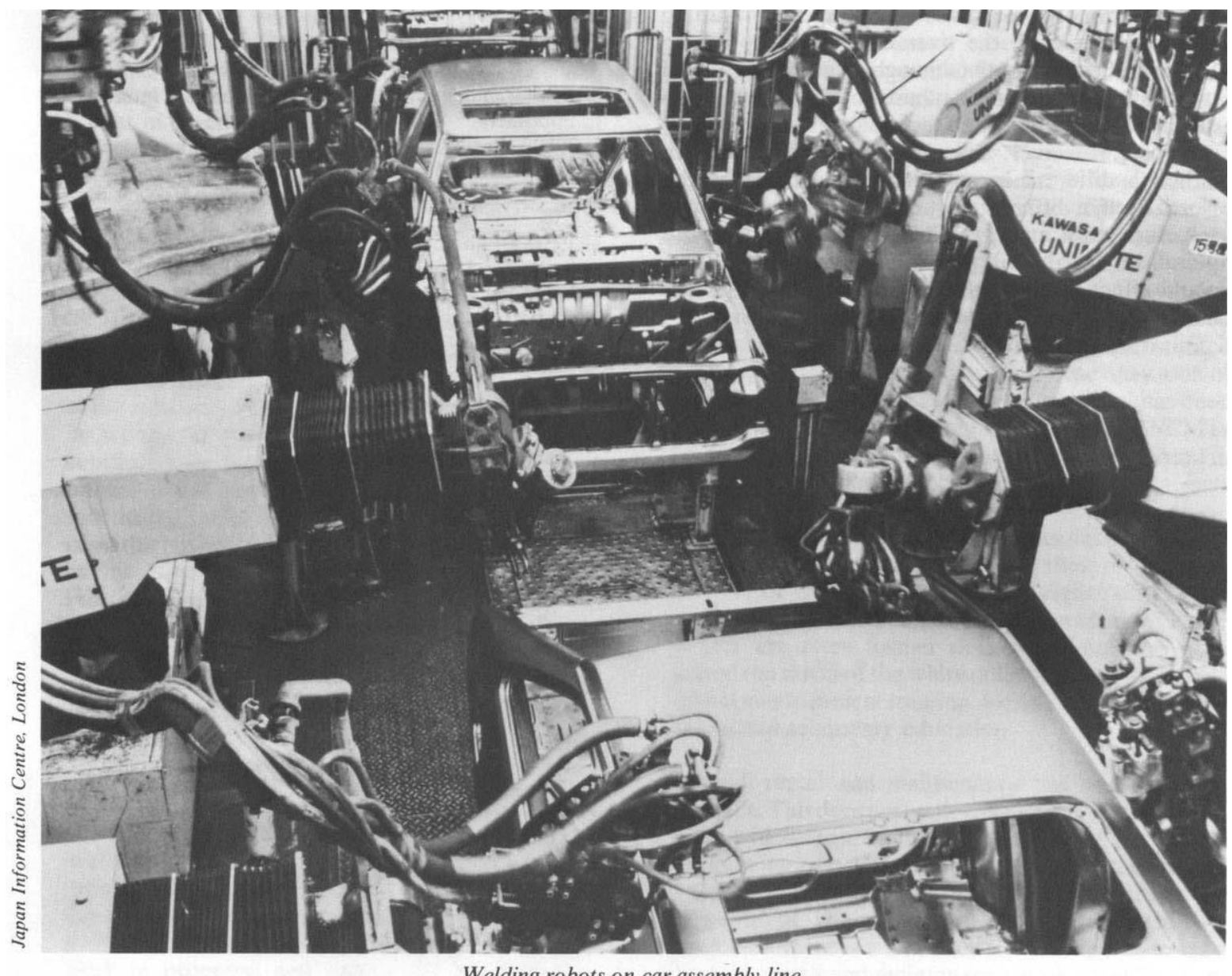

Welding robots on car assembly line.

the masses will result, which will create new demand patterns involving not only demand for foreign travel with its consequences for the tourist industry in the South, but also the desire to maximize the purchasing power of given incomes, which implies changes in international trade.

So far the information aspects of automation and the latter's impact on services in general has hardly been mentioned. Yet, the Northern geo-technology of microelectronics will have a major impact on the concentration of information: the know-how, knowwhere and know-whom. This implies a further detrimental effect on comparative advantage, since those who control information control, to some extent, economic and even political life. Undoubtedly the South will also try to reduce its dependence in this area. The more it operates as a block, the more chance it will have of successfully reducing the degree of dependency.

\section{Conclusion}

Microelectronic technological changes will affect comparative advantage in the following way: a few Northern countries, which have a lead on the basis of $\mathrm{R}$ and $\mathrm{D}$, practical applications and diffusion will have a comparative advantage $v i s-a-$-vis the rest of the world for some time to come. This may push the rest of the North into a dependency relation-but even more so for the South. Nevertheless, differences in the speed and direction of diffusion amongst areas and countries creates in itself a basis for international trade based on differences in absolute and relative comparative advantage. On the basis of the output-speciality criterion trade will, in principle, remain strong within the North, within the South and between both, although it may in the short run decrease somewhat. Much depends on responses made to this technological challenge in those countries which are initially dependent. If the response is defensive, trade may suffer. Finally, for the NICs and possibly even for the South as a whole, the 
new technology may also open up new trading opportunities. Still, the overall dependency of the South vis-à-vis the North (although in fact differentiated by country) will, on the basis of these Northern developed and controlled technologies, undoubtedly increase. However, since a similar phenomenon, although different in magnitude, will occur in the North itself, a different economic and political power structure may emerge. This could imply a more pluralistic North-South relation, which in its turn, could affect patterns of comparative advantage and hence the international division of labour.

\section{References}

Boon, G. K., 1980a, Technology and Employment in Footwear Manufacturing Sijthoff and Noordhoff International Publishers

$-1980 \mathrm{~b}$, 'Present and future trends in the international divi sion of labour' (mimeo), to be published in The Proceedings of the International Economic Association Meeting Mexico City

-1981, Technology Transfer in Fibres, Textile and Apparel, Sijthoff and Noordhoff International Publishers

-1982, Technology Behaviour and Assessment, forthcoming 